\title{
Efficacy of the Surgical Management of Amiodarone-induced Thyrotoxicosis
}

\author{
${ }^{1}$ Marilla Dickfos, ${ }^{2}$ Robert Franz
}

\section{ABSTRACT}

Introduction: Amiodarone can be a life-saving medication; however, it can also cause amiodarone-induced thyrotoxicosis (AIT). Though rare, AIT is a complex and life-threatening side effect, which can cause significant cardiac dysfunction and lead to cardiac failure. Primary treatment is with thionamides, perchlorates, and steroids. However, a small subgroup does not respond and their cardiovascular function continues to deteriorate. This select group is referred for a semi-elective total thyroidectomy. Without surgical removal of their thyroid gland, these patients will continue to deteriorate, with a 30 to $50 \%$ mortality rate for those not operated on.

Aim: The aim of this case series was to assess for any indicators as to when these patients should be referred for total thyroidectomies and the efficacy of this method of treatment.

Materials and methods: A case series of patients with AIT treated with a total thyroidectomy from 1998 to 2015 was used to assess the efficacy of and indicators for surgery.

Results: Total thyroidectomy results in efficient and significant improvement in the patient's biochemistry and symptoms. The patient's symptoms and options for medical therapy have an influence on the duration of the trial of medical therapy.

Conclusion: Surgery is an effective and efficient treatment for AIT. However, there does not appear to be a specific indicator for when this treatment should be instigated. A case-by-case approach should be adopted when treating these complicated patients.

Clinical significance: Clinicians should see surgery as an effective and efficient treatment for AIT. The timing of surgery should be assessed on a case-by-case basis considering the patient's clinical status and therapeutic options and not as a last resort.

Keywords: Amiodarone, Thyroidectomy, Thyroiditis, Treatment efficacy.

How to cite this article: Dickfos M, Franz R. Efficacy of the Surgical Management of Amiodarone-induced Thyrotoxicosis. World J Endoc Surg 2017;9(3):79-87.

Source of support: Nil

Conflict of interest: None

\footnotetext{
${ }^{1,2}$ Consultant

${ }^{1}$ Department of General Surgery, Royal Brisbane and Women's Hospital, Brisbane, Queensland, Australia

${ }^{2}$ Department of General Surgery, The Prince Charles Hospital Brisbane, Queensland, Australia

Corresponding Author: Marilla Dickfos, Consultant, Department of General Surgery, Royal Brisbane and Women's Hospital Brisbane, Queensland, Australia, Phone: +61431265210 e-mail: marilladickfos@hotmail.com
}

\section{INTRODUCTION}

Amiodarone, a class III antiarrhythmic, can be a lifesaving medication in the treatment of tachyarrhythmias. It has been shown to improve survival rates in patients with heart failure and effective in treating cardiac arrhythmias, which are refractory to other medications. ${ }^{1,2}$ Amiodarone is generally administered in doses 50 to 100 times the daily iodine requirement. This iodine load can trigger increased thyroid hormone synthesis and release. Yet, amiodarone also decreases peripheral deiodination of thyroxine $\left(\mathrm{T}_{4}\right)$ to triiodothyronine $\left(\mathrm{T}_{3}\right)$ by inhibiting liver type I iodothyronine 5 -deiodination of $\mathrm{T}_{4}{ }^{3}$

This interference in thyroid function can lead to AIT, a complex and life-threatening side effect with an incidence of 3 to $5 \%$ in Australia. ${ }^{4}$ It is difficult to manage due unresponsiveness to medication, worsening of tachyarrhythmias in patients with poor cardiac function, and the possibility of needing to continue amiodarone to control an arrhythmia. ${ }^{4}$ The AIT can cause significant cardiac dysfunction and lead to cardiac failure. The onset of AIT is variable and can occur anytime from 2 to 47 months after use of amiodarone. ${ }^{5}$

Thyrotoxicosis is diagnosed by clinical signs and symptoms and thyroid function tests (TFTs). The signs and symptoms can include relapse and/or worsening of an arrhythmia with cardiac insufficiency, nervousness, tremor, fatigue, muscle weakness, and weight loss. ${ }^{6}$ The onset is rapid and fulminant. The TFTs usually show a low thyroid-stimulating hormone (TSH), a high $\mathrm{T}_{4}$, and normal or slightly high $\mathrm{T}_{3}$. There is little evidence of an autoimmune mechanism, as serum antithyroglobulin, antimicrosomal, and antithyrotropin receptor antibodies are usually undetectable.

Other forms of iodine-induced thyrotoxicosis are generally managed conservatively due to their selflimiting nature. The long half-life of amiodarone ( 107 days) means that patients are exposed for a significant duration after cessation. Conservative management may not be suitable due to the possible worsening of preexisting arrhythmias, cardiac failure, angina pectoris, and cardiomyopathy. ${ }^{1,7}$ When feasible, current practice is to withdraw amiodarone to stop the prolongation of thyrotoxicosis; however, this may not alter 
the immediate clinical situation. Additionally, due to the inhibition of peripheral deiodination, there can be a paradoxical worsening of the patient's condition on cessation of therapy.

There is a male predisposition with a male:female ratio of $\sim 3: 1$ and a tendency to occur in iodine-deficient areas. There are also three types; type I occurs in abnormal thyroid glands via a Jod-Basedow phenomenon, where the iodine loading unmasks underlying thyroid autonomy. Type II is a destructive thyroiditis leading to the release of preformed hormones from an intrinsically normal thyroid gland and type III is a mixed type. The histopathology for all types shows marked destruction of follicles, with inflammation and fibrosis. ${ }^{8}$

The medical management is challenging, poorly understood, and lacks a proven, consistent therapeutic armamentarium. ${ }^{1,9}$ In Australia, type I is typically managed by the simultaneous administration of thionamides and potassium perchlorate. Type II is commonly treated by steroids and improvement is often seen within 2 weeks. ${ }^{9-11}$ Radioiodine therapy is not feasible due to the suppressed iodine uptake, delayed effect, and potential for further hormone release. ${ }^{12,13}$ Mixed forms are best treated with a combination of the aforementioned medications. ${ }^{14}$

Treatment may take up to 4 months to become effective and no regimens have demonstrated reliable success. These patients generally have preexisting cardiac dysfunction and do not tolerate hyperthyroidism well; they require timely resolution of their AIT. ${ }^{15}$ Chemical treatments also have significant side effects including nephrotoxicity and bone marrow suppression. Corticosteroids inhibit 5-monodeiodinase activity and can even worsen $\mathrm{T}_{4}$ thyrotoxicosis. ${ }^{16}$

Overall, the difficulties with medical management are:

- Cessation of amiodarone may worsen cardiac dysfunction

- Cessation of amiodarone can cause paradoxical rise in $\mathrm{T}_{3}$, worsening thyrotoxicosis

- Delay in achieving a euthyroid state with medication

- Never inducing a response with medication

- Side effects of the medication

Plasmapheresis and hemodialysis can provide acute relief but only transient effects and are extremely expensive and impractical in the long term.

The small selection of patients who do not respond to medical treatments have uncontrolled thyrotoxicosis, the potential to develop a thyrotoxic crisis, and can develop end-stage cardiac failure. This select group is referred for a semi-elective total thyroidectomy. ${ }^{9}$ There is minimal research on this subset of patients and no guidelines as to when surgery is indicated.
Without a thyroidectomy, these patients will continue to deteriorate, and have a mortality rate of 30 to $50 \% .{ }^{12}$ This rate is reduced to 0 to $13 \%$ when a thyroidectomy is performed. ${ }^{17}$ These patients can have significant improvement in their functional status post-thyroidectomy. ${ }^{4}$ Usually, total thyroidectomy is a last resort, but it may need to be considered earlier in the treatment algorithm as it allows for rapid control and continuation of amiodarone. ${ }^{4}$ It has proven to be not only a life-saving measure, but also the only way to continue amiodarone therapy. ${ }^{2}$

The current agreed upon indications for surgery are:

- When amiodarone is essential

- Type I or mixed AIT, as the underlying disorder may be similar to Grave's disease and may maintain the thyrotoxicosis

- Patients awaiting heart transplant

- Failure of antithyroid treatment

The current difficulty lies in defining the criteria of medical treatment failure in a standardized fashion, to avoid emergency thyroidectomy. ${ }^{18,19}$ Surgery has been shown to rapidly treat the thyrotoxicosis and patients recover within a few days rather than enduring months of treatment without a definitive outcome. ${ }^{8}$ Further research is needed to develop guidelines for which patients and for how long should medications be trialed.

The aim of this case series is to analyze these patients for any signs as to when surgery is indicated. The case series also aims to demonstrate the efficacy of a total thyroidectomy as treatment for AIT.

\section{MATERIALS AND METHODS}

A retrospective analysis was performed from January 1998 to November 2015. Pathology records were screened for thyroid tissue and patients who underwent a total thyroidectomy to treat AIT at The Prince Charles Hospital (TPCH), Australia were obtained and reviewed. Ethics approval was obtained from the Human Research and Ethics Committee (HREC) at TPCH.

The patients' demographics, comorbidities, history of previous thyroid pathology and function, amiodarone indications, doses, and duration prior to the diagnosis were noted. The patients' thyrotoxic symptoms, medical therapy (including agents used, doses, and duration), indication for thyroidectomy, and cardiac status were documented. Cardiac and thyroid function markers were assessed at three specific time points: Diagnosis, preoperative, and postoperative.

Specifically, the factors assessed included TFTs $\left(\mathrm{T}_{4}, \mathrm{~T}_{3}, \mathrm{TSH}\right)$ antithyroglobulin autoantibodies, antibodies to thyroid peroxidase (ATPO), anti-TSH receptor autoantibodies, heart rate and rhythm, blood pressure, left ventricular ejection fraction (LVEF), echocardiography findings, 
Table 1: Demographics, amiodarone use, and AIT treatment

\begin{tabular}{|c|c|c|c|c|c|c|c|c|}
\hline Patient & Age & Sex & $\begin{array}{l}\text { Indication for } \\
\text { amiodarone } \\
\text { therapy }\end{array}$ & $\begin{array}{l}\text { Duration of } \\
\text { amiodarone } \\
\text { therapy before } \\
\text { diagnosis } \\
\text { (months) }\end{array}$ & $\begin{array}{l}\text { Duration of } \\
\text { thyrotoxicosis } \\
\text { before surgery } \\
\text { (weeks) }\end{array}$ & Medications used & $\begin{array}{l}\text { Duration of } \\
\text { medication } \\
\text { trial (weeks) }\end{array}$ & $\begin{array}{l}\text { Side } \\
\text { effects from } \\
\text { medications }\end{array}$ \\
\hline 1 & 70 & $M$ & VT & 40.5 & 8 & Carbimazole, prednisone & 8 & $\mathrm{Nil}$ \\
\hline 2 & 82 & M & AFib & 38 & 9 & $\begin{array}{l}\text { Beta-blockers, carbimazole, } \\
\text { and prednisone }\end{array}$ & 9 & Nil \\
\hline 3 & 51 & M & SVT/Aflutter & 5 & 11 & $\begin{array}{l}\text { Beta-blockers, carbimazole, } \\
\text { and prednisone }\end{array}$ & 11 & Nil \\
\hline 4 & 52 & M & VF & 9 & 1.5 & Carbimazole, prednisone & 1.5 & Neutropenia \\
\hline 5 & 68 & M & AFib & 20 & 13 & $\begin{array}{l}\text { Beta-blockers, carbimazole, } \\
\text { and prednisone }\end{array}$ & 13 & Nil \\
\hline 6 & 51 & $\mathrm{~F}$ & VT & $>29$ & 2 & $\begin{array}{l}\text { Beta-blockers, carbimazole, } \\
\text { and prednisone }\end{array}$ & 2 & $\begin{array}{l}\text { Felt exercise } \\
\text { tolerance } \\
\text { decreasing }\end{array}$ \\
\hline 7 & 59 & M & AFib & 15 & 7 & $\begin{array}{l}\text { Beta-blockers, carbimazole, } \\
\text { and prednisone }\end{array}$ & 7 & Nil \\
\hline 8 & 52 & M & VT & 43 & 6 & $\begin{array}{l}\text { Beta-blockers, carbimazole, } \\
\text { prednisone, and } \\
\text { cholestyramine }\end{array}$ & 6 & Nil \\
\hline 9 & 48 & M & AFib & 21 & 2.5 & $\begin{array}{l}\text { Beta-blockers, carbimazole, } \\
\text { prednisone, cholestyramine, } \\
\text { and lithium }\end{array}$ & 2.5 & Nil \\
\hline 10 & 63 & M & AFib & 33 & 7.5 & $\begin{array}{l}\text { Beta-blockers, carbimazole, } \\
\text { and prednisone }\end{array}$ & 7.5 & Nil \\
\hline 11 & 34 & $\mathrm{~F}$ & Aflutter & 14 & 14 & $\begin{array}{l}\text { Beta-blockers, carbimazole, } \\
\text { and prednisone }\end{array}$ & 14 & Nil \\
\hline
\end{tabular}

VT: Ventricular tachycardia; AFib: Atrial fibrillation; SVT: Supraventricular tachycardia; Aflutter: Atrial flutter; VF: Ventricular fibrillation

and patient symptoms. All surgeries were performed under general anesthesia. Thyroidectomy was as total as possible in each case.

\section{RESULTS}

\section{Amiodarone-induced Thyrotoxicosis Group}

Eleven patients underwent total thyroidectomies under general anesthesia for AIT from January 1998 to November 2015. The salient features of the data are summarized in the tables. Table 1 illustrates the patient demographics, their amiodarone use, and AIT treatment.

Table 2 demonstrates the clinical state of the AIT patients prior to their operations.

Table 3 illustrates the postoperative state of the patient as well as the histopathology findings.

Graphs 1 and 2 provide a graphical representation of each patient's $\mathrm{T}_{4}$ levels over time. Arrows indicate the medications initiated, dose changes, and the date of surgery.

\section{DISCUSSION}

\section{Background on TPCH}

This research was performed at TPCH. The TPCH is a 630-bed, tertiary referral hospital, and located $10 \mathrm{~km}$ from
Brisbane city (the capital of the state of Queensland). It is the premier cardiac service for the State of Queensland, as well as northern New South Wales. It provides specialized services in complex interventional cardiology, structural heart disease, and cardiac electrophysiology. It is the center for specialized state-wide services including heart and lung transplantation, adult cystic fibrosis, adult congenital heart disease, advanced heart failure; percutaneous valve therapies, and complex cardiac care.

This background provides the foundation to a better understanding of this group of patients. The patients identified at TPCH with AIT came from a cohort of cardiac cripples; each one had significant cardiac comorbidities. This setting is considerably different from other hospitals and must be kept in mind when interpreting the results.

\section{Demographics}

The demographics of the cases and their amiodarone use reflect what has previously been documented in the literature. Firstly, as shown in Table 1, AIT is seen more frequently in males. This study showed a male:female ratio of 9:2, and this is comparable to the literature which quotes a 3:1 distribution. ${ }^{4}$ This is hypothesized to be due to the higher frequency of males suffering from cardiovascular disease and being treated with amiodarone. 
Table 2: Preoperative thyroid and cardiac functions

\begin{tabular}{|c|c|c|c|c|}
\hline Patient & Preoperative symptoms & Preoperative cardiac function & $\begin{array}{l}\text { Preoperative } T_{4} \\
\text { (pmol/L) }\end{array}$ & $\begin{array}{l}\text { Preoperative } \\
T S H(m U / L)\end{array}$ \\
\hline 1 & Chest pain, palpitations, syncope, diaphoresis & $\begin{array}{l}\text { Pacemaker in situ: HR: } 68 \text {, } \\
\text { BP: } 140 / 75 \text {, EF: } 20 \%\end{array}$ & 39 & 0.2 \\
\hline 2 & $\begin{array}{l}\text { Dizziness, palpitations, sensation of missed } \\
\text { beats, tremor, diarrhea, increased appetite, } \\
\text { and weight loss }\end{array}$ & $\begin{array}{l}\text { Atrial fibrillation: HR: } 120, \mathrm{BP}: 130 / 80 \text {, } \\
\text { EF: } 58 \% \text { (8 months prior) }\end{array}$ & 65 & 0.08 \\
\hline 3 & Palpitations & $\begin{array}{l}\text { Sinus rhythm: HR: } 70, \mathrm{BP}: 115 / 70 \text {, } \\
\text { EF: } 68 \% \text { ( } 9 \text { years prior) }\end{array}$ & 22 & 0.05 \\
\hline 4 & Diarrhea (in the setting of infective colitis) & $\begin{array}{l}\text { Sinus rhythm: HR: } 55 \text {, BP: } 150 / 80 \text {, } \\
\text { EF: Not documented }\end{array}$ & 29 & 0.1 \\
\hline 5 & Palpitations, tremor, weight loss, and irritability & $\begin{array}{l}\text { Sinus rhythm: HR: } 65 \text {, BP: } 125 / 70 \text {, } \\
\text { EF: } 39 \%\end{array}$ & 34 & 0.05 \\
\hline 6 & Occasional palpitations & $\begin{array}{l}\text { Pacemaker in situ: HR: 78, BP: } \\
\text { 135/60, EF: } 27-30 \%\end{array}$ & 71 & 0.1 \\
\hline 7 & $\begin{array}{l}\text { Orthopnea, PND, SOBOE, AF, decreased } \\
\text { appetite, tiredness }\end{array}$ & $\begin{array}{l}\text { Atrial fibrillation: HR: } 90, \mathrm{BP}: 110 / 70 \text {, } \\
\text { EF: } 25 \%\end{array}$ & 46 & 0.1 \\
\hline 8 & Lethargy, decreased exercise tolerance. & $\begin{array}{l}\text { Sinus rhythm: HR: } 60, \mathrm{BP}: 150 / 70 \text {, } \\
\text { EF: } 63 \%\end{array}$ & 73 & 0.2 \\
\hline 9 & $\begin{array}{l}\text { Shortness of breath, tachycardia, hot flushes, } \\
\text { and rigors }\end{array}$ & $\begin{array}{l}\text { Sinus rhythm: HR: } 122, \mathrm{BP}: 170 / 80 \text {, } \\
\text { EF: } 67 \%\end{array}$ & 120 & 0.05 \\
\hline 10 & $\begin{array}{l}\text { Lethargy, weight loss, diarrhea, and vomiting. } \\
\text { Fever over a month on background of infective } \\
\text { endocarditis. Encephalopathic with MODS }\end{array}$ & $\begin{array}{l}\text { Atrial fibrillation: HR: } 70, \mathrm{BP}: 130 / 51 \text {, } \\
\text { EF: } 50-60 \%\end{array}$ & 47 & 0.5 \\
\hline 11 & $\begin{array}{l}\text { Increased peripheral edema, increased fluid } \\
\text { retention, nauseated, abdominal discomfort } \\
\text { and lethargic }\end{array}$ & $\begin{array}{l}\text { Pacemaker in situ: HR: } 60 \text {, BP: } \\
\text { 90/43, EF: } 19 \%\end{array}$ & 76 & 0.05 \\
\hline
\end{tabular}

HR: Heart rate; BP: Blood pressure; MODS: Multiple organ dysfunction syndrome

Table 3: Postoperative state and histopathology

\begin{tabular}{|c|c|c|c|c|c|}
\hline Patient & Histopathology & $\begin{array}{l}\text { Weight of } \\
\text { gland (grams) }\end{array}$ & $\begin{array}{l}\text { Postoperative } \\
T_{4}(\text { pmol/L) }\end{array}$ & $\begin{array}{l}\text { Postoperative } \\
\text { symptoms }\end{array}$ & Postoperative cardiac function \\
\hline 1 & Consistent with AIT & 14.15 & 9.1 & No symptoms & $\begin{array}{l}\text { Pacemaker in situ: HR: 69, BP: } 110 / 60 \text {, } \\
\text { EF: Not documented }\end{array}$ \\
\hline 2 & Consistent with AIT & 37 & 8.1 & $\begin{array}{l}\text { Chest tightness and } \\
\text { shortness of breath }\end{array}$ & $\begin{array}{l}\text { Atrial fibrillation: HR: 103, BP: } 130 / 75 \text {, } \\
\text { EF: Not documented }\end{array}$ \\
\hline 3 & Consistent with AIT & 26 & 11 & Sore throat & $\begin{array}{l}\text { Sinus rhythm: HR: } 70, B P: 115 / 70, \\
\text { EF: Not documented }\end{array}$ \\
\hline 4 & Consistent with AIT & 33.7 & 22 & No symptoms & $\begin{array}{l}\text { NSR: HR: } 84, \text { BP: } 156 / 102 \text {, EF: Not } \\
\text { documented }\end{array}$ \\
\hline 5 & Consistent with AIT & 26 & 13 & Ongoing tremor & $\begin{array}{l}\text { Sinus rhythm: HR: } 58, B P: 120 / 70 \text {, } \\
\text { EF: Not documented }\end{array}$ \\
\hline 6 & Consistent with AIT & 27.9 & 67 & No symptoms & $\begin{array}{l}\text { Pacemaker in situ: HR: 65, BP: } \\
\text { 105/60, EF: } 32 \%\end{array}$ \\
\hline 7 & Consistent with AIT & 33 & 6.1 & $\begin{array}{l}\text { Pain over surgical } \\
\text { site }\end{array}$ & $\begin{array}{l}\text { Atrial fibrillation: HR: } 99, \mathrm{BP}: 161 / 89 \text {, } \\
\text { EF: Not documented }\end{array}$ \\
\hline 8 & Consistent with AIT & 62 & * & No symptoms & $\begin{array}{l}\text { Sinus rhythm: HR: } 70, B P: 143 / 77 \text {, } \\
\text { EF: Not documented }\end{array}$ \\
\hline 9 & Consistent with AIT & 61 & 96 & No symptoms & $\begin{array}{l}\text { Sinus rhythm: HR: } 108, \mathrm{BP}: 150 / 80 \text {, } \\
\text { EF: Not documented }\end{array}$ \\
\hline 10 & $\begin{array}{l}\text { Unremarkable thyroid } \\
\text { tissue }\end{array}$ & 25 & 14 & $\begin{array}{l}\text { Ongoing } \\
\text { encephalopathy }\end{array}$ & $\begin{array}{l}\text { Atrial fibrillation: HR: } 76, \mathrm{BP}: 170 / 60 \text {, } \\
\text { EF: } 50 \%\end{array}$ \\
\hline 11 & $\begin{array}{l}\text { Diffuse enlargement with } \\
\text { attacking follicles and } \\
\text { infiltrating colloid (no } \\
\text { diagnosis given) }\end{array}$ & 29.6 & 16 & No symptoms & $\begin{array}{l}\text { Pacemaker in situ: HR: } 60, \mathrm{BP}: 90 / 43 \text {, } \\
\text { EF: Not documented }\end{array}$ \\
\hline
\end{tabular}

HR: Heart rate; BP: Blood pressure; ${ }^{*} p<0.05$ 

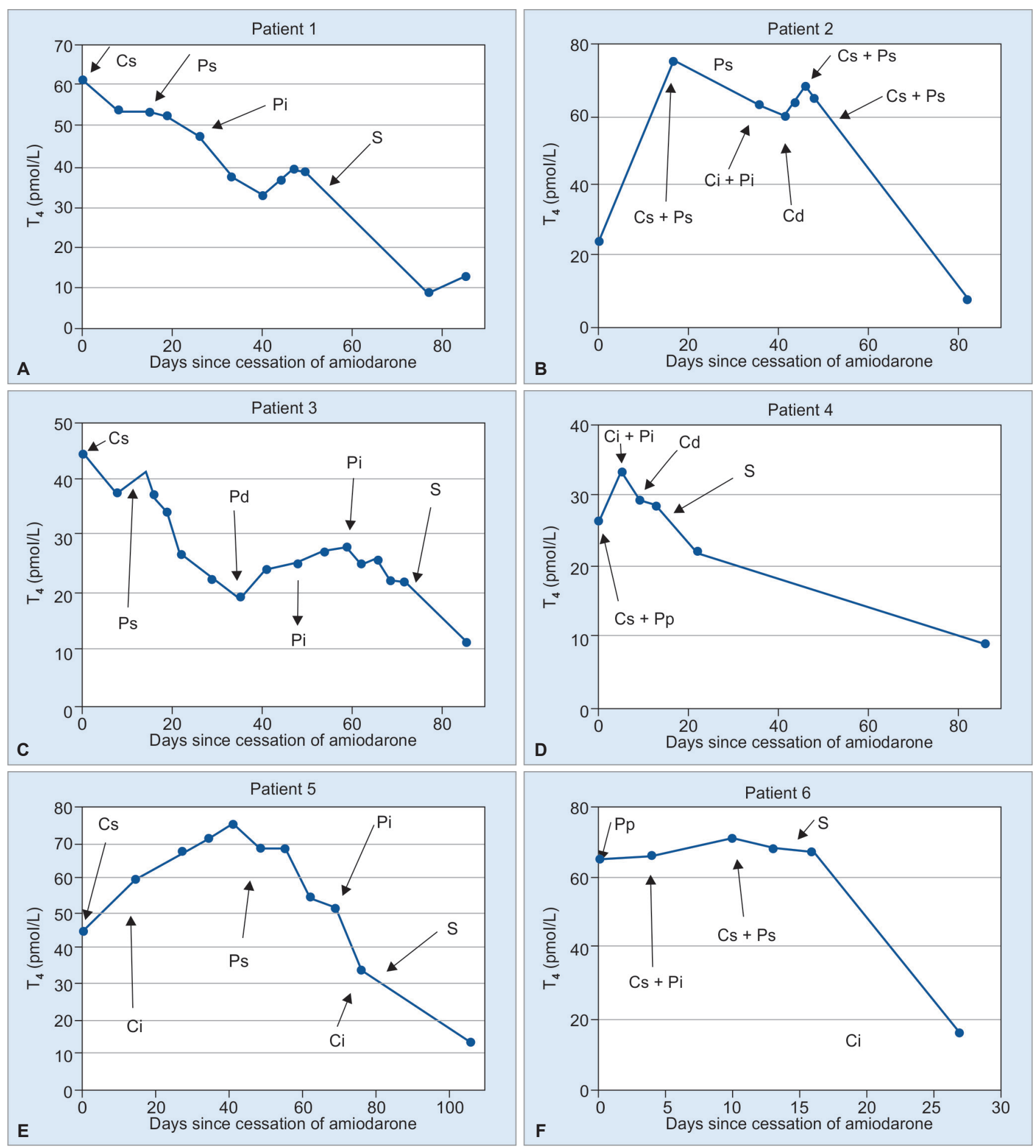

Graphs 1A to $F: T_{4}$ values from diagnosis to the immediate postoperative period for the first six patients. Pp: Previously on prednisone; Cs: Carbimazole started; Ps: Prednisone started; Ci: Carbimazole increased; Pi: Prednisone increased; Cd: Carbimazole decreased; Pd: Prednisone decreased; S: Surgery

Secondly, there is a variable duration of amiodarone use before onset of symptoms, which has also been previously documented. ${ }^{5}$ Mariotti et $\mathrm{l}^{5}$ stated the duration of time before onset ranged between 2 and 47 months and, as shown in Table 1, all the values from this study fall within that range. Thirdly, the time between diagnosis and surgery is also highly variable. This is likely related to the lack of guidelines available to direct management of these patients. However, all patients were operated on within the half-life of amiodarone ( 107 days); thus, despite all patients ceasing amiodarone, there may have been a residual amount in each patient's system. Hence, no comment can be made about self-resolution of AIT after elimination of amiodarone in these patients.

\section{Amiodarone-induced Thyrotoxicosis Diagnosis}

The diagnosis of AIT was made for each patient by their elevated $\mathrm{T}_{4}$, depressed TSH values, negative antibody 

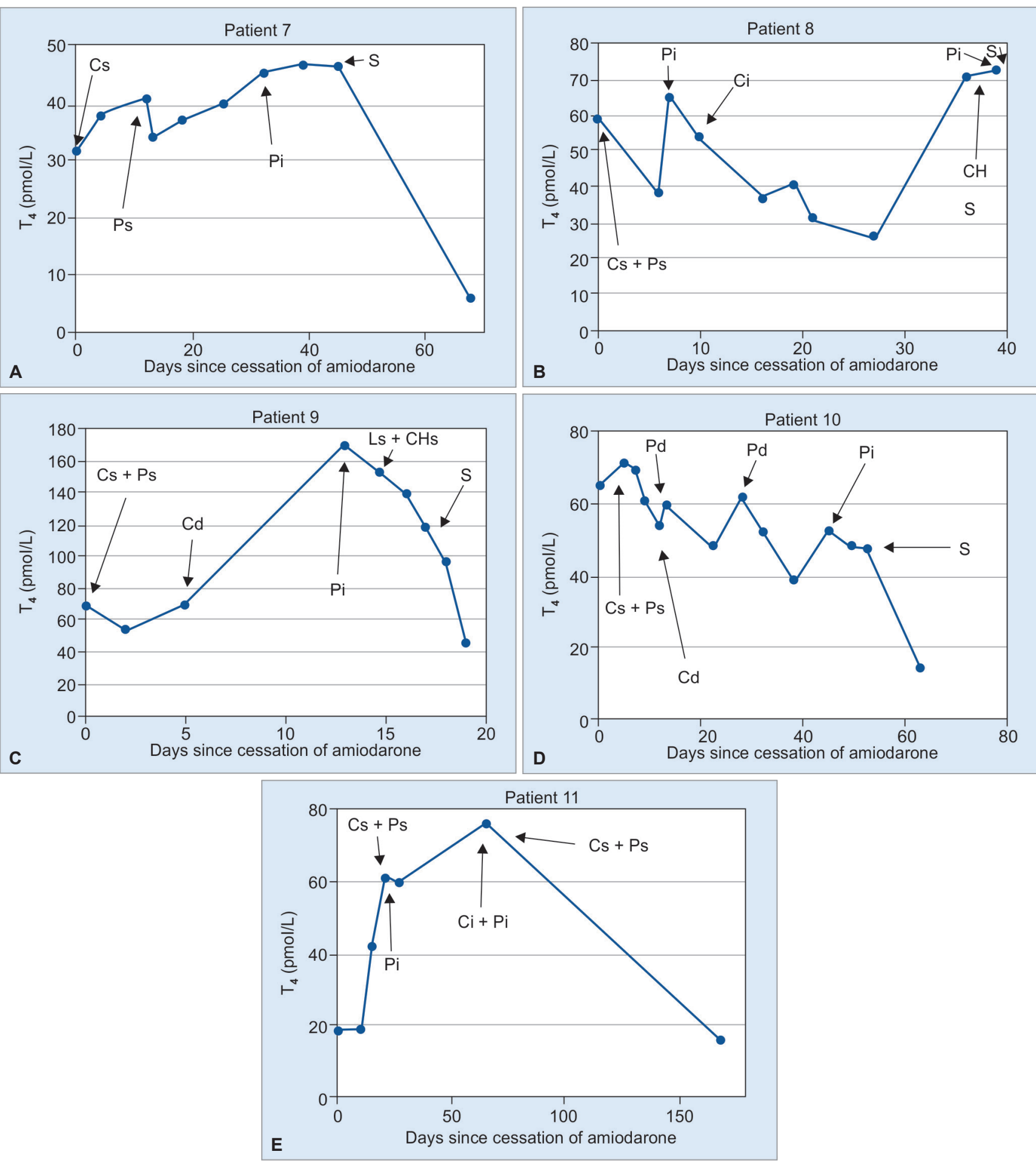

Graphs 2A to $E: T_{4}$ values from diagnosis to the immediate postoperative period for the remaining five patients. Pp: previously on prednisone; Cs: Carbimazole started; Ps: Prednisone started; Ci: Carbimazole increased; Pi: Prednisone increased; Cd: Carbimazole decreased; Pd: Prednisone decreased; CHs: Cholestyramine started; Ls: Lithium started; S: Surgery

levels, and history of amiodarone use. Two patients did have elevated ATPO, but were diagnosed as having AIT by the endocrinology teams involved and later confirmed on histological analysis.

The type of AIT diagnosed was not documented in any of the 11 cases. As determining between types of AIT can be difficult, this is understandable. However, as the type of AIT determines the treatment recommended, it is difficult to comment on the appropriateness of the treatment regimens.

\section{Amiodarone-induced Thyrotoxicosis Treatment}

The medical treatment regimens for the AIT patients typically initiated one of two ways; carbimazole alone before adding prednisone $(\mathrm{n}=4$; patients $1,3,5$, and 7$)$ and carbimazole with prednisone combined ( $\mathrm{n}=7$, but 
two patients were currently on prednisone when the diagnosis was made). This would suggest that those four patients were initially thought to have AIT type I. Only one of those patients provided a previous history of thyroid dysfunction. This demonstrates a lack of consistency with diagnosing and treating the subtypes of this disease.

The duration of the trial of carbimazole alone lasted 22 days on average with a range of 12 to 48 days. Prednisone was then added to the treatment regime of these patients due to the lack of response to carbimazole. It is likely that the patients were re-evaluated to have a diagnosis of "mixed-type" AIT.

Except for two patients, all were treated with betablockers; however, these medications were part of each patient's regular medications prior to the diagnosis of AIT. This is to be expected as these patients had significant cardiac dysfunction.

Two patients had additional medications trialed; patient 8 was given cholestyramine and patient 9 was given cholestyramine and lithium. Cholestyramine is an ion exchange resin, which has been shown to interfere with endogenous thyroid hormone absorption and blocks enterohepatic circulation. ${ }^{20}$ Lithium has been shown to inhibit thyroid hormone release and reduce iodination of tyrosine residues, but is infrequently used due to its toxicity profile. ${ }^{21}$ Both agents were used late in the treatment of the patients and likely as a last attempt to control the thyrotoxicosis before referring to surgery.

Though every patient was eventually treated with both carbimazole and prednisone, the treatment regimens varied. This may be due to the variety of physicians leading the care of the patients. This study spanned over 17 years and the patients were cared for by different doctors. Without guidelines, the treatment of these patients would have been completely physician-dependent, as would have been the decision to refer to surgery. During this 17-year period, there were developments in the definition, pathophysiology, and management of AIT, which needs to be taken into consideration. Thus, a prearranged treatment regime for this group of patients was not likely. However, the dose ranges were consistent and similar to other studies in the literature. ${ }^{10}$

\section{Timing of Surgery}

Graphs 1 and 2 demonstrate the efficacy of the medications for each patient. The data points collected are innately determined by the regularity of blood samples taken and analyzed. However, a general trend can be identified throughout the graphs. The medications used tended to have either a temporary or small effect on the $\mathrm{T}_{4}$ values. There was no evidence of a threshold $\mathrm{T}_{4}$ level or duration of medical therapy that prompted a referral for surgery. The duration of medical treatment ranged from 1.5 to 14 weeks and the highest preoperative $\mathrm{T}_{4}$ values ranged from 34 to $170 \mathrm{pmol} / \mathrm{L}$. From these results, it would suggest that every patient is being treated on an individual basis and the decision to refer to surgery cannot be made based on time or biochemical values.

The complexities of these patients and the multiple factors that influence the decision to operate can best be exemplified by reviewing patients individually. By comparing two patients, who underwent very different durations of thyrotoxicosis prior to surgery, the significant differences that may have affected the decision to operate are exposed.

Patient 9 endured a long and unstable postoperation recovery from a heart transplant he had 2 months prior to developing AIT. He underwent thyroid surgery within 2.5 weeks due to his inability to compensate for the increased stress on his cardiovascular system. He was encephalopathic pre- and postoperation secondary to his multiple organ dysfunction syndrome. He had a regular heart rate of $125 \mathrm{bpm}$ (beats per minute) at diagnosis and a blood pressure of 200/80 mm Hg. These values continued both pre- and postoperation. His cardiac function, as measured by an echocardiogram 2 days prior to his surgery, showed a normal left ventricle size and function, an LVEF of $65 \%$, normal right ventricular size and function, biatrial dilatation, and normal valves. He suffered no complications from the surgery, but unfortunately passed away 4 days postoperation due to causes unrelated to the thyroid surgery.

In comparison, patient 11 was operated on 14 weeks after being diagnosed. Her background included multiple congenital cardiac defects, which had been repaired, atrial flutter with a pacemaker, and an automatic implantable cardioverter defibrillator (AICD). She had significant cardiac dysfunction with an LVEF of $19 \%$, left ventricular end diastolic diameter of $6 \mathrm{~cm}$ (normal 3.9-5.3 cm), a severely dilated and dysfunctional right ventricle with a right ventricular systolic pressure of $48 \mathrm{~mm} \mathrm{Hg}$ (normal range for $<50$ years old $21.6-33 \mathrm{~mm} \mathrm{Hg}$ ), as well as grade $2 / 4$ mitral regurgitation and $3 / 4$ tricuspid regurgitation. ${ }^{22}$

However, despite her severe cardiac condition, she was permitted to be thyrotoxic for 14 weeks before she was deemed suitable for an operation. She only had two medication changes, one was the day prior to the operation. However, during this time, she remained hemodynamically stable with a paced heart rate of $60 \mathrm{bpm}$ and a blood pressure of 99/43 preoperation and 134/54 postoperation. The symptoms she was experiencing were increased peripheral edema, increased fluid retention, nausea, abdominal discomfort, and lethargy. She 
recovered well from the operation, suffering only mild hypocalcemia, but passed away from primary cardiac graft transplant failure after receiving a heart transplant 2 years later.

It may be suggested that patient 9 was referred to surgery with more urgency due to his $\mathrm{T}_{4}$ level. Patient $9 \mathrm{did}$ have the highest $\mathrm{T}_{4}$ level prior to surgery at $120 \mathrm{pmol} / \mathrm{L}$. However, there was no obvious correlation between time to surgery and $T_{4}$ values as the second highest $T_{4}$ value (patient $11, \mathrm{~T}_{4}=76 \mathrm{pmol} / \mathrm{L}$ ) waited 14 weeks before having an operation. This comparison suggests that the most important feature in dictating when a patient was their current clinical condition.

Another factor that must be taken into consideration is the potential therapies available to the patients. This is best exemplified by comparing patients 1 and 4 . Patient 1 underwent surgery 8 weeks after diagnosis, whereas patient 4 had surgery within 1.5 weeks. Patient 1 had poor cardiac function with an EF of $25 \%$ on the background of dilated cardiomyopathy, an AICD, mild coronary artery disease, an aortic valve replacement (mechanical), obesity, obstructive sleep apnea, depression, gastroesophageal reflux disease, chronic kidney disease (CKD, stage IV), hypertension, hypogonadism, secondary hypothyroidism, iron deficiency, restless legs and had experienced a right cerebellar embolic stroke. Patient 4 had undergone a heart transplant the year prior to developing AIT and had better cardiac function. However, he did have other comorbidities; type II diabetes mellitus, gout, CKD, obesity, previous abdominal hernia repair, and gastrectomy. Both patients had similar heart rates, blood pressures, and $\mathrm{T}_{4}$ values. One main difference between these two patients is that patient 4 had been on prednisone since the heart transplant. This may have influenced management as a glucocorticoid could not be added, but only increased in dosage for management of the symptoms. This may have prompted earlier surgery in patient 4 in comparison with patient 1, who had the worse cardiac function out of the two patients. Patient 4 may have also been referred earlier to surgery due to his immunosuppressed state.

Thus, from analyzing the patients' clinical status, comorbidities, cardiac function, and $\mathrm{T}_{4}$ levels with respect to time-to-surgery, it has been shown that poor clinical status and lack of potential treatments may be potential indicators for a shorter trial of medical management before surgical intervention. Yet, as the timing of referral to surgery is a subjective decision made by individual physicians, it is difficult to specifically identify an indicator.

\section{Medication Side Effects}

Patient 4 was the only patient to experience a side effect, which could clearly be linked to the medication. To address this complication, the dose of carbimazole was decreased. Though this did not result in rebounding $\mathrm{T}_{4}$ values, the patient's response to the medication did appear to slow and they underwent surgery within 4 days. Patient 6 suffered a decrease in their exercise tolerance; however, a causal link to the medication is debatable as it may have been due to a decline in their cardiac function.

Except for patient 8, who was lost to follow-up postoperatively, surgery had a larger and more definitive effect on the $T_{4}$ values than medication. $T_{4}$ values were recorded from time of diagnosis to one or two measurements postoperation. The ongoing follow-up of $\mathrm{T}_{4}$ values postoperation was redundant due to the initiation of thyroxine in all patients.

It is difficult to determine the speed of the effect of surgery due to the period between the surgery and reassessing $\mathrm{T}_{4}$ values postoperatively. Patients 3, 4, 6, 9, and 10 all had TFTs taken within 2 weeks of surgery, whereas the remaining 6 patients had TFTs reassessed much later. Within 2 weeks, patients 3, 6, 9, and 10 had all at least halved their $\mathrm{T}_{4}$ values. However, patient 6 had a $\mathrm{T}_{4}$ value recorded on day 2 postoperation, which was very similar to their preoperative value and patient 9 only experienced a $20 \%$ decrease in $\mathrm{T}_{4}$ value by day 1 postoperation.

Patient 4 had a decrease in $\mathrm{T}_{4}$ from 29 to $22 \mathrm{pmol} / \mathrm{L} 2$ days after the operation, but had no further blood tests until day 52 postoperative $\left(T_{4}=9.2 \mathrm{pmol} / \mathrm{L}\right)$. As the other patients had blood tests at a much later time, it is impossible to determine if their $\mathrm{T}_{4}$ values had decreased at a similar rate, and then plateaued, or if the decline was more gradual. Based on the results available, it would suggest that within 2 weeks, surgery was very effective in over $80 \%(n=5 / 6)$ of cases. A structured prospective trial with an agreed upon sampling frequency would assist in determining the speed of the surgical effect.

\section{LIMITATIONS}

As previously mentioned, there were a few limiting features of this study. Firstly, the small sample size inhibits the use of statistical analysis due to the lack of power in the study. This is a factor of studying rare diseases. To overcome this, recruitment of more facilities to be involved in prospective trials or to collate and analyze data from preexisting research or facilities is recommended.

Another limitation in assessing the efficacy of surgery in treating AIT is the lack of structured regularity in TFTs. As previously mentioned, a prospective study with regular and structured blood tests would assist in overcoming this limitation.

This study is a retrospective analysis of chart notes and this lends itself toward bias. There is bias in the interpretation and documentation. Though the charts were thoroughly reviewed to source all information, not 
all information was documented; this was more evident in the older charts. Lack of information results in an incomplete assessment of all the patients and prevents solid conclusions being documented.

Only a single patient was lost to follow-up, due to further medical review occurring at a distant private facility; however, this accounts for almost $9 \%$ of the cohort. Once again, a larger trial would improve the robustness of the study.

\section{CONCLUSION}

Surgery efficiently treated AIT and allowed patients to become euthyroid via chemical replacement. The $\mathrm{T}_{4}$ values, duration of medical trial, and previous medical comorbidities/cardiac function did not correlate to timing of a thyroidectomy. The only potential indications were the severity of the symptoms and the range of treatments available to the patient. Those with more severe symptoms were treated quicker than those who appeared to be compensating for their hyperthyroid status, despite significant comorbidities. Those currently on prednisone appeared to be referred quicker than those with a full complement of treatments available. With further research, guidelines may be created based on the patients' clinical status and current medications.

\section{CLINICAL SIGNIFICANCE}

This case series has shown the efficacy of surgery in treating AIT. This research provides physicians with evidence of how prolonged medical therapy may not be the best treatment for these patients and how surgery can quickly cure their condition. This research also shows how different each of these patients are and how each case must be addressed on an individual and case-bycase basis.

\section{REFERENCES}

1. Bartalena L, Wiersinga WM, Tanda ML, BogazziF, PiantanidaE, Lai A, Martino E. Diagnosis and management of amiodaroneinduced thyrotoxicosis in Europe: results of an international survey among members of the European Thyroid Association. Clin Endocrinol (Oxf) 2004 Oct;61(4):494-502.

2. Hamoir E, Meurisse M, Defechereux T, Joris J, Vivario J, Hennen G. Surgical management of Amiodarone-associated thyrotoxicosis: too risky or too effective? World J Surg 1998 Jun;22(6):537-543.

3. Claxton S, Sinha S, Donovan S, Greenaway T, Hoffman L, Loughhead M, Burgess J. Refractory amiodarone-associated thyrotoxicosis: an indication for thyroidectomy. Aust N Z J Surg 2000 Mar;70(3):174-178.

4. Gough J, Gough IR. Total thyroidectomy for amiodaroneassociated thyrotoxicosis in patients with severe cardiac disease. World J Surg 2006 Nov;30(11):1957-1961.

5. Mariotti S, Loviselli A, Murenu S, Sau F, Valentino L, Mandas A, Vacquer S, Martino E, Balestrieri A, Lai ME. High prevalence of thyroid dysfunction in adult patients with beta-thalassemia major submitted to amiodarone treatment. J Endocrinol Invest 1999 Jan;22(1):55-63.

6. Meurisse M, Gollogly L, Degauque C, Fumal I, Defechereux T, Hamoir E. Latrogenic thyrotoxicosis: causal circumstances, pathophysiology and principles of treatment - review of the literature. World J Surg 2000 Nov;24(11):1377-1385.

7. Farwell AP, Abend SL, Huang SK, Patwardhan NA, Braverman LE. Thyroidectomy for amiodarone-induced thyrotoxicosis. JAMA 1990 Mar;263(11):1526-1528.

8. Gough I, Meyer-Witting M. Surgery and anaesthesia for amiodarone-associated thyrotoxicosis. Aust N Z J Surg 2000 Mar;70(3):155-156.

9. EatonSE, EuintonHA, Newman CM, Weetman AP, BennetWM. Clinical experience of amiodarone-induced thyrotoxicosis over a 3-year period: role of colour-flow Doppler sonography. Clin Endocrinol (Oxf) 2002 Jan;56(1):33-38.

10. Mehta AN, Vallera RD, Tate CR, Sager RA, Welch BJ. Total thyroidectomy for medically refractory amiodarone-induced thyrotoxicosis. Proc (Bayl Univ Med Cent) 2008 Oct;21(4): 382-385.

11. Rajeswaran C, Shelton R, Gilbey S. Management of amiodarone-induced thyrotoxicosis. Swiss Med Wkly 2003 Nov;133(43-44):579-585.

12. Tomisti L, Materazzi G, Bartalena L, Rossi G, Marchello A, Moretti M, De Napoli L, Mariotti R, Miccoli P, Martino E, et al. Total thyroidectomy in patients with amiodarone-induced thyrotoxicosis and severe left ventricular systolic dysfunction. J Clin Endocrinol Metab 2012 Oct;97(10):3515-3521.

13. Bartalena L, Bogazzi F, Martino E. Amiodarone-induced thyrotoxicosis: a difficult diagnostic and therapeutic challenge. Clin Endo 2002 Jan;56(1):23-24.

14. Lorberboym M, Schachter P. Drug-induced thyrotoxicosis: the surgical option. Isr Med Assoc J 2007 Feb;9(2):79-82.

15. Houghton SG, Farley DR, Brennan MD, van Heerden JA, Thompson GB, Grant CS. Surgical management of amiodarone-associated thyrotoxicosis: mayo clinic experience. World J Surg 2004 Nov;28(11):1083-1087.

16. Meurisse M, Hamoir E, D'Silva M, Joris J, Hennen G. Amiodarone-induced thyrotoxicosis: is there a place for surgery? World J Surg 1993 Sep-Oct;17(5):622-627.

17. Fideler FJ, Dieterich H-J, Schroeder TH. Fatal outcome during anaesthesia induction in a patient with amiodarone-induced thyrotoxicosis. Eur J Anaesthesiol 2007 Oct;25:336-348.

18. Pierret C, Tourtier JP, Pons Y, Merat S, Duverger V, Perrier E. Total thyroidectomy for amiodarone-associated thyrotoxicosis: should surgery always be delayed for pre-operative medical preparation? J Laryngol Otol 2012 Jul;126(7):701-705.

19. Franzese CB, Fan CY, Stack BC Jr. Surgical management of amiodarone-induced thyrotoxicosis. Otolaryngol Head Neck Surg 2003 Nov;129(5):565-570.

20. Mercado M, Mendoza-Zubieta V, Bautista-Osorio R, Espinozade los Monteros AL. Treatment of hyperthyroidism with a combination of methimazole and cholestyramine. J Clin Endocrinol Metab 1996 Sep;81(9):3191-3193.

21. Carroll R, Matfin G. Endocrine and metabolic emergencies: thyroid storm. Ther Adv Endocrinol Metab 2010 Jun;1(3): 139-145.

22. Armstrong DW, Tsimiklis G, Matangi MF. Factors influencing the echocardiographic estimate of right ventricular systolic pressure in normal patients and clinically relevant ranges according to age. Can J Cardiol 2010 Feb;26(2):e35-e39. 